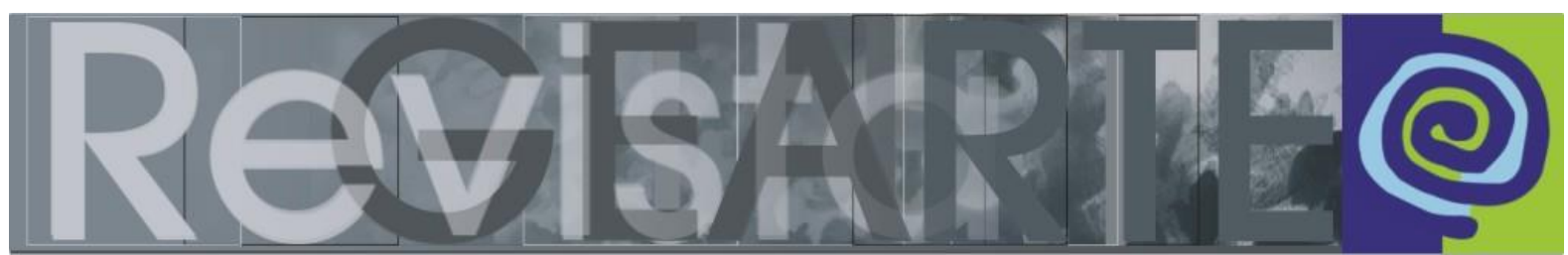

ISSN 2357-9854

\title{
Audiovisual e semiótica: algumas aproximações resultantes dos estudos de uma adaptação literária para a linguagem da animação
}

\author{
Diego Maria Cardoso (Universidade da Região de Joinville — Univille, Joinville/ SC, Brasil) \\ Rita Inês Petrykowski Peixe (Instituto Federal de Santa Catarina - IFSC, Campus \\ Itajaí, Itajaí/SC,Brasil)
}

\begin{abstract}
RESUMO - Audiovisual e semiótica: algumas aproximações resultantes dos estudos de uma adaptação literária para a linguagem da animação - $\mathrm{O}$ campo do audiovisual é muito amplo e abarca inúmeros desdobramentos. O encantamento pelo cinema, mais precisamente pelo campo da animação, foi a motivação necessária para um trabalho de conclusão de curso direcionado à produção de um curta-metragem em animação. A curiosidade pelas mais diversas formas de adaptação de obras literárias em audiovisuais gerou o desafio em mergulhar nos estudos da semiótica discursiva, com a pretensão de investigar as minúcias de uma produção literária infantil. A obra intitulada $\mathrm{O}$ coelhinho do halo azul, refere-se ao texto escolhido para ser objeto de investigação e propõe um convite a tangenciar esse mundo complexo e intrigante da linguística, pleiteando, com os instrumentos de análise da semiótica discursiva, um espaço mais amplo nesse universo audiovisual. Esse é o foco do presente artigo, que apresenta, por fim, a articulação pontuada do plano de conteúdo do texto para o plano de expressão na linguagem de animação.
\end{abstract}

PALAVRAS-CHAVE

Audiovisual. Animação. Semiótica. Adaptação literária.

ABSTRACT - Audiovisual and semiotics: some approaches resulting from the study of the adaptation of a literary piece into the animation language - Audiovisuals's field is very ample and covers innumerable developments. A fascination with cinema, precisely animation, was the necessary motivation for the course's conclusion paper to be directed towards a production of an animated short film. A curiosity for the most diverse forms of adaptation of literary works into audiovisuals generated the challenge of immersing into the studies of discursive semiotics, intending to investigate the singularities of children's literature. The work entitled The blue halo rabbit refers to the chosen text under study and proposes an invitation to regard this incredibly complicated and intriguing world of linguistics, using the instruments of discursive semiotics, a wider space in the audiovisual universe. It's what the present article addresses, presenting, finally, the punctuated articulation of the text's plane of content to the plane of expression in animation's language.

KEYWORDS

Audiovisual. Animation. Semiotics. Literary adaptation.

\section{Apresentação}

As reflexões apresentadas neste artigo dizem respeito a um trabalho de conclusão de curso de Graduação em Design - habilitação em Animação Digital, cujo objeto ocupou-se em fundamentar e adaptar uma obra literária infantil para a linguagem de animação. Centralizando as atenções no texto literário, o presente artigo

CARDOSO, Diego Maria; PEIXE, Rita Inês Petrykowski. Audiovisual e semiótica: algumas aproximações 274 resultantes dos estudos de uma adaptação literária para a linguagem da animação.

Revista GEARTE, Porto Alegre, v. 3, n. 2, p. 274-288, maio/ago. 2016.

Disponível em: http://seer.ufrgs.br/gearte 
tem como fio condutor os estudos da semiótica discursiva, extraindo os conceitos de sentido no plano de conteúdo e no plano de expressão para, posteriormente, demonstrar como eles foram utilizados na linguagem de animação. A pretensão auspiciosa de produzir um curta-metragem em animação já previa, no início do projeto, uma série de investigações do campo audiovisual como, por exemplo, as referências, pesquisas e definições das etapas de desenvolvimento para animação (roteiro, edição, finalização). Porém, para o presente artigo, não serão propostas discussões relativas às etapas de produção, mantendo-se as atenções nos estudos atinentes à semiótica discursiva do texto literário direcionadas à linguagem de animação.

Nesse sentido, a proposta do artigo, sendo um recorte de um estudo mais amplo, tem como escopo examinar um texto literário com base nos estudos da semiótica discursiva para, posteriormente, aplicar seus conceitos na linguagem de animação.

\section{O texto como objeto de análise}

Alguns aspectos relacionados à obra literária necessitam ser considerados, na certeza de que toda contextualização de um objeto de análise é sempre profícua para maior aproximação e clareza dos referenciais nos quais se pautarão as apreciações.

Nesse caso, vale ressaltar que o conto intitulado $O$ coelhinho do halo azul, do autor catarinense Adolfo Bernardo Schneider, foi produzido no final da década de 50 para ser apresentado em um programa de rádio, na véspera do natal. A obra inicia com uma visão conservadora do autor sobre o comportamento infantil da época e, na sequência, apresenta a narrativa propriamente dita.

A história refere-se a "uma homenagem singela, embora tardia, à alma cristalina e pura de Hans Christian Andersen" (SCHNEIDER, 1959, s. p.), escritor dinamarquês, criador de narrativas infantis como $O$ patinho feio, A Pequena Sereia, $A$ Rainha da Neve. Além disso, Hans Christian Andersen é o condutor da narrativa desta obra escrita por Schneider.

Sinteticamente, a narrativa relata que, na véspera do natal, em uma aldeia na Europa, a menina Mariazinha, que vive com a sua avó, percebendo as dificuldades na 
sua casa e na aldeia, por conta do rigoroso inverno, parte para a floresta em busca da boa fada. Como a menina não sabe onde encontrá-la, recebe a ajuda de um coelhinho do halo azul. Após encontrar com a boa fada, Mariazinha acorda e percebe que tudo foi um sonho. A história tem como desfecho a aldeia e, contrariamente à situação anterior, as coisas começam a melhorar e aquele sonho se torna realidade.

Em relação à presente pesquisa, tem-se como ponto relevante a condição de que o material de origem não possui edições posteriores, sendo que o único exemplar existente encontra-se de posse da pesquisadora Eliane Santana Dias Debus, em Florianópolis. Dando espaço a um ilustre autor da cidade de Joinville, ao produzir um material audiovisual acerca dos seus escritos, é possível disseminar, tanto no meio acadêmico quanto no âmbito do ensino fundamental e médio, os conteúdos da literatura regional. Nesse sentido, a ênfase é também no caráter educativo, histórico e cultural da investigação proposta.

\section{Abordagem semiótica}

As correntes teóricas sobre a semiótica aconteceram a partir do século XX e tornaram-se conhecidas como a ciência dos signos, da significação e da cultura. A expansão ininterrupta de signos nos mais diversos meios de linguagens exige instrumentos de estudo que sejam objetivos e esclarecedores (SANTAELLA, 2002).

Além da teoria do signo proposta por Charles Sanders Peirce ${ }^{1}$, Ferdinand de Saussure (1857-1913) apresentou estudos sobre a estrutura da língua que repercutiu em muitas áreas do conhecimento, incluindo a semiótica discursiva (SANTAELLA, 1983).

Para Saussure (1973) o signo linguístico seria a unidade mínima da significação da língua e sua definição possui dupla face: o significante (imagem acústica) e o significado (conceito): "Esses dois elementos estão intimamente unidos e um reclama o outro" (SAUSSURE, 1973, p. 80). O diagrama na sequência apresenta o exemplo de Saussure.

1 Charles Sanders Peirce (1839-1914) foi um filósofo, cientista e matemático norte-americano que propôs uma teoria semiótica ligada à fenomenologia (SANTAELLA, 2002). 
Figura 1 - Diagrama que ilustra o conceito de signo linguístico de Saussure

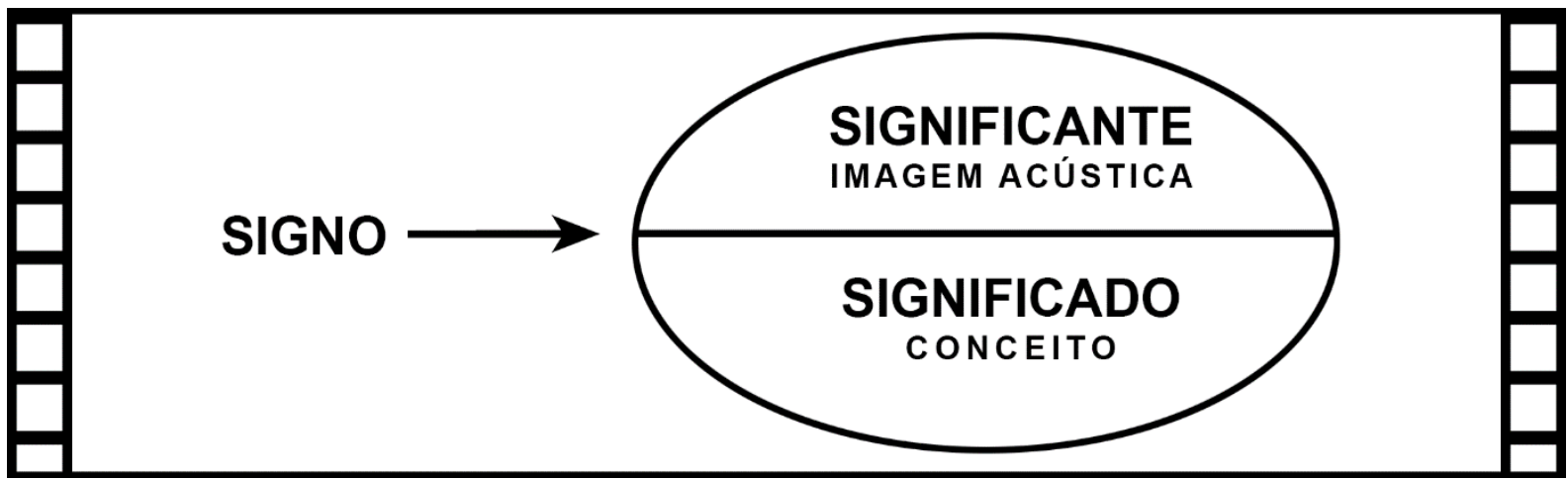

Fonte: Saussure (1973, p. 81).

O significante (imagem acústica) pode ser uma palavra ou um texto, sendo aquilo que se apresenta à pessoa. Já o significado (conceito) é aquilo que se apresenta à mente, dando sentido a alguma coisa. O conceito é, portanto, um processo psíquico que cada pessoa elabora através do seu próprio repertório. $A$ definição de signo acontece quando ele é colocado em oposição a outro signo, ou seja, o signo deve ser contextualizado para que se possa defini-lo em relação a outros signos.

Os estudos de Saussure no modelo linguístico deram a base necessária para o estruturalismo nos anos 60. Além da linguística, o estruturalismo ofereceu suporte para outros campos como o da antropologia, matemática, biologia e das ciências sociais. Dentro da semiótica, o estruturalismo se preocupa com a ideia do signo, da estrutura e do sistema sígnico (NÖTH, 1999).

Santaella comenta que "quando se tem em mira a análise e interpretação de certos tipos de signos, os narrativos, por exemplo [...] a semiótica greimasiana dispõe de meios capazes de realizar essa tarefa de modo muito mais proveitoso" (SANTAELLA, 2002, p. 16).

Nessa perspectiva, a continuação dos estudos semióticos na presente investigação seguiram pela linha greimasiana, também conhecida como semiótica discursiva. Os estudos relacionados a esse campo são apresentados no tópico que segue. 


\section{O texto como objeto semiótico}

Os estudos da semiótica discursiva no campo da linguística possuem um instrumental de análise que pode ser aplicado ao texto, no qual se busca compreender a sua significação. A investigação ora proposta teve como base os autores Barros (1997), Fiorin (1995), Fontanille (2007), Pietroforte (2007), Landowski (1995) e Oliveira (1995; 2009).

Acerca da semiótica francesa é importante constar que ela teve como seu fundador Algirdas Julien Greimas (1917-1992), que concebeu uma teoria de análise estrutural do texto por meio do estudo de sua significação, presente no livro Semântica Estrutural, publicado em 1966 (LANDOWSKI, 1995). Greimas dá continuidade à obra de Saussure e de Hjelmslev², propondo "uma teoria da significação que dê conta das condições de produção e de compreensão do sentido" (FIORIN, 1995, p. 6). O percurso gerativo de sentido consiste em métodos que demonstram a significação do texto por meio de consecutivas etapas.

Para deixar mais clara a ideia de sentido, Fontanille (2007, p. 31) define o sentido como "em primeiro lugar, uma direção: dizer que um objeto ou uma situação tem um sentido é, na verdade, dizer que eles tendem a algo".

Os sistemas semissimbólicos são definidos pela relação do plano de expressão e do plano de conteúdo. Compreendendo que os sistemas expressivos reproduzem sensorialmente os temas e conteúdos, Hjelmslev mostrou como é possível separar o plano de expressão e o plano de conteúdo (BARROS, 1997). O plano de expressão busca compreender como se dá a manifestação do conteúdo. Já o plano de conteúdo busca o significado do texto, de maneira objetiva (PIETROFORTE, 2007).

Quando é feita uma relação entre o plano de expressão e o plano de conteúdo, temos uma função sígnica, havendo, propriamente, uma ligação entre elementos ou valores variáveis (NÖTH, 1999).

2 Louis Hjelmslev (1899-1965) foi o fundador da Escola de Copenhague de linguística estruturalista. Dando continuidade aos conceitos de Saussure, Hjelmslev apresentou a sua teoria da homologia, em que o plano de expressão e o plano de conteúdo devem ser estudados separadamente (NÖTH, 1999). 
Temos como objeto de análise o texto, colocando-se, portanto, a necessidade de explicar o que ele nos apresenta. Segundo Barros (1997), a definição de texto é muito mais ampla do que o próprio texto oral ou escrito "uma poesia, um romance, um editorial [...] uma história em quadrinhos, um filme, uma canção popular" (BARROS, 1997, p. 8).

A teoria semiótica da estrutura do texto de Barros (1997) é caracterizada da seguinte maneira:

- conciliação da análise interna e externa do texto: A primeira é destinada ao objeto de significação, o sentido analisado dentro do texto. A segunda, por objeto de comunicação, o contexto sócio-histórico em que o texto está envolvido;

- construção do sentido pelo percurso gerativo do sentido, que vai do mais simples e abstrato ao mais complexo e concreto. As etapas do percurso são divididas em três níveis, sendo nível fundamental, nível narrativo e nível discursivo.

O método apresentado por Barros (1997) será elencado nos sucessíveis tópicos, tendo o texto da obra infantil $O$ coelhinho do halo azul como objeto de análise na construção de sentido.

\section{Nível fundamental}

A oposição das categorias semânticas fundamentais foi estabelecida através dos sentidos nas relações que compõem o texto. Estas correspondem ao plano de conteúdo, sendo que alegria vs. aflição são os termos categóricos que geram sentido no texto $O$ coelhinho do halo azul. O quadro subsequente revela o sentido do percurso semântico fundamental. 
Figura 2 - Percurso semântico fundamental do texto $O$ coelhinho do halo azul

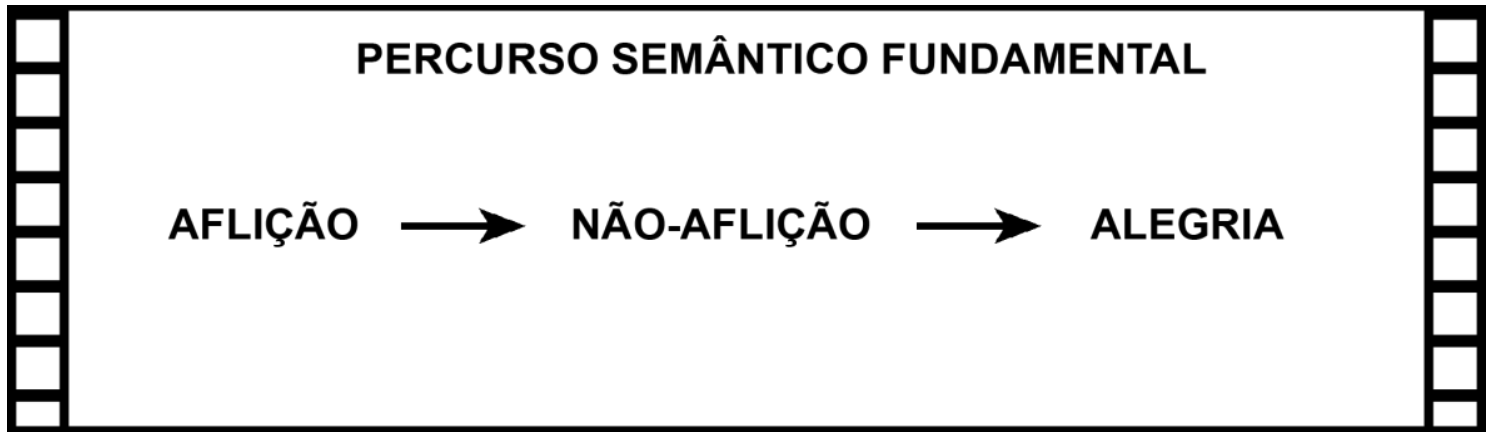

Fonte: Elaborado pelo autor.

$\mathrm{Na}$ história que serve como referência para esse estudo, a aldeia estaria ameaçada pelo tempo frio, o que impedia os moradores de conseguirem alimentos e lenha para manterem suas casas aquecidas. Desse modo, a continuação desta situação poderia levar a uma grande tragédia dentro da aldeia. Por essa razão, o uso do termo fundamental aflição possui uma relação com o termo disfórico (negativo) no sentido do texto. Os elementos disfóricos são manifestados no início da história como: "a carestia era muito grande", "a vovozinha da menina sempre estava aflita", "os habitantes da aldeia, que ficavam [...] olhando tristemente para o tempo, que não queria clarear" e o "frio e [...] fome, que reinavam em todas as casas da aldeia" (SCHNEIDER, 1959, s.p.).

Quando Mariazinha acorda, percebe que, além do tempo ter melhorado, as necessidades da aldeia estavam sendo supridas. $O$ termo fundamental alegria é relacionado ao termo eufórico (positivo) no sentido do texto. Os elementos eufóricos são manifestados no final da história como: "agora, já não sentia mais esse frio [...] um calor brando enchia a sala", "um cheirinho tão bom, de doces, que somente a querida vovozinha sabia fazer" e "a rua estava mais bonita do que nunca" (SCHNEIDER, 1959, s.p.).

Pode-se observar que $O$ coelhinho do halo azul tem como conteúdo mínimo fundamental a negação da aflição, como sentido negativo, e a afirmação da alegria como sentido positivo.

Os próximos tópicos tratarão de apresentar uma análise narrativa do texto, apontando as transformações evidentes dos participantes e de seus papéis na história. 


\section{Nível narrativo}

No início da narrativa, a aflição é um objeto de estado virtual que envolve todos na aldeia. Mariazinha manifesta o desejo de [querer] transformar a aflição em alegria, que seria a superação do rigoroso inverno que castiga a aldeia.

Mariazinha (sujeito) é conduzida pelo coelhinho do halo azul (adjuvante) a encontrar a Boa Fada (destinador), pois busca a alegria (objeto) para a aldeia (destinatário) que sofre as consequências do rigoroso frio (opositor).

Conforme o quadro seguinte, o Programa Narrativo (PN) está na relação de Mariazinha (S 1) querer o Objeto de Valor (OV), que está em conjunção ( $\mathrm{n})$ com a Boa Fada (S 2).

Figura 3 - Programa Narrativo na relação de Mariazinha (S1) querer o Objeto de Valor (OV), que está em conjunção ( $\mathrm{n}$ ) com a Boa Fada (S2)

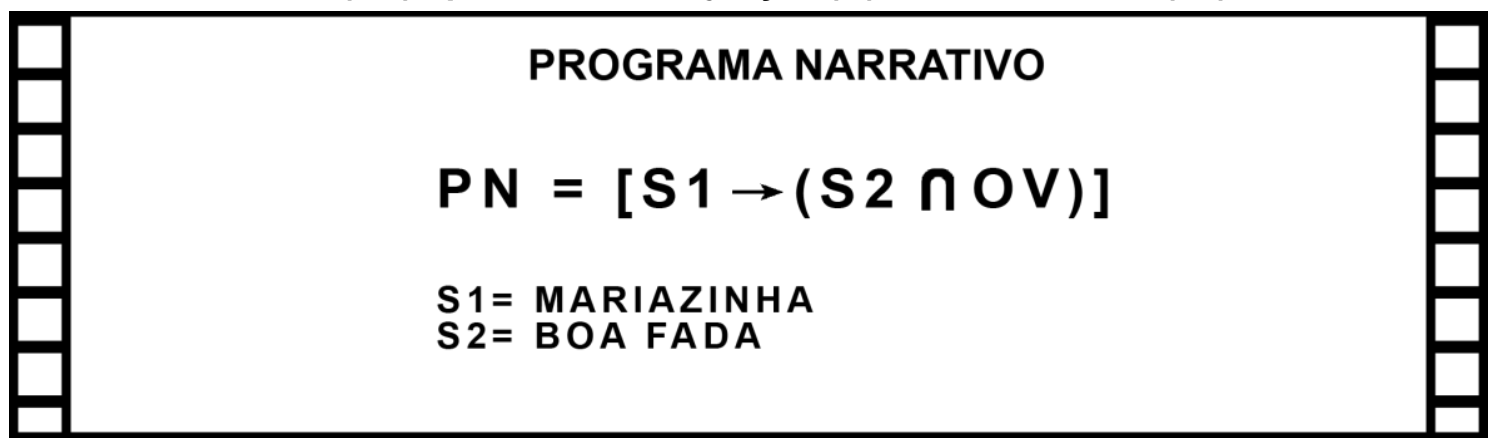

Fonte: Elaborado pelo autor.

O sujeito de estado "Mariazinha" mantém relação de junção com vários objetos como "a vovozinha [...] sempre estava aflita", "fome quase o dia inteiro" e "os habitantes da aldeia, que ficavam [...] olhando tristemente para o tempo, que não queria clarear" (SCHNEIDER, 1959, s.p.).

O destinador-manipulador "Boa Fada" oferece a Mariazinha o objeto de valor diferente do qual ela queria anteriormente: "a Boa Fada Ihe oferecia diamantes e pedras preciosas", mas Mariazinha recusa: "não era isto que eu desejava de coração. Queria eu pedir que hoje, no Dia de Natal, todos os habitantes de minha aldeia fossem felizes" (SCHNEIDER, 1959, s.p.). 
O sujeito do fazer "Boa Fada" transforma a relação de junção do sujeito "Mariazinha" com os objetos "frio" e "fome". Havendo mudança de estado em "cheirinho tão bom de doce que somente a querida vovozinha sabia fazer", "um calor brando enchia a sala" e "havia terminado de nevar, a rua estava varrida, as casas estavam iluminadas [...] todas enfeitadas com velinhas acesas de todas as cores". Nesse ponto, ocorre a modalização do [querer] para [saber] e [alegria] em Mariazinha.

A performance de Mariazinha é, portanto, bem sucedida, após ela acordar em sua própria casa. A alegria é alcançada com as indicações de: "um calor brando enchia a sala" e "chegou aqui uma grande carroça, carregada de presentes para os lenhadores e suas famílias" (SCHNEIDER, 1959, s.p.).

\section{Nível discursivo}

A obra $O$ coelhinho do halo azul possui recursos discursivos variados para fabricar o conto. A operação de desembreagem enunciativa em terceira pessoa suscita um distanciamento dos papéis e acontecimentos, criando a ilusão de objetividade. Schneider escolheu o contador de história Hans Christian Andersen para narrar o conto $O$ coelhinho do halo azul. Em alguns momentos, as crianças interagem com Andersen, fazendo indagações a respeito da história. Schneider (1959, s.p.) descreve no início do conto:

\footnotetext{
Mas isto vocês sabem com certeza muito melhor do que eu.

Como a gente sempre tem fome, quando se é pequeno e sempre se gosta de comer!

UMA PEQUENA BEM GORDUCHA: - Sim. nós também gostamos sempre de comer! (Irrompe um côro de risadas alegres!)

- Pois bem!
}

Por ser um texto direcionado às crianças, a linguagem é simples, clara, com expressões como: "Mariazinha", "Vovozinha", "bondosa", "bem mansinho" e "cascatinha". Os acontecimentos são bem descritos e, em alguns momentos exemplificados, estimulando a imaginação.

O texto mistura o personagem do cristianismo "menino Jesus" com outros míticos: "Boa Fada" e "coelhinho do halo azul". Mesmo fabricando uma história lúdica e fantasiosa, outros elementos da doutrina cristã estão presentificados como "igreja", 
"pastor", "Mãe do menino Jesus" e "Natal". Por ser uma história natalina, a escolha desses aspectos possui coerência, visto que, no prefácio do livro, Schneider também lutava contra elementos que ele citou como "decomposição moral".

O discurso do conto possui a intenção e o objetivo de passar bons hábitos e valores como generosidade e compaixão. Como visto anteriormente, Mariazinha busca a alegria da aldeia no dia de natal, arriscando-se na floresta e negando riquezas oferecidas a ela pela boa fada.

\section{O texto sincrético como animação}

O texto sincrético é constituído pela articulação de várias linguagens, desde que elas possam produzir um significado. As sequências de imagens, gráficos, sons e locução são componentes linguísticos diversificados que compõem uma animação, sendo considerados um texto sincrético. Assim, podemos dizer também que um espetáculo teatral, uma ópera ou uma obra cinematográfica podem ser caracterizados como um texto sincrético.

Greimas e Courtés (2008) definem o sincretismo como aquilo que relaciona mais de um termo ou categoria heterogênea, reunindo todos em uma grandeza semiótica. Uma trilha sonora que dá suporte a uma animação é um exemplo de um termo que complementa a ação que vemos na tela.

Oliveira (2009) comenta que em um texto sincrético é comum que determinada linguagem possa preponderar em relação às demais. Dessa maneira, algumas linguagens ficam mais claras que outras. Com isso, a análise sincrética se utiliza de meios que tratam de relacionar a articulação do plano de expressão para que seja possível compreender o seu significado, ou seja, o plano de conteúdo. Segundo a autora, os planos de expressão de um texto sincrético podem ser definidos pelas categorias cromáticas, eidéticas, topológicas e matéricas.

Nessa perspectiva, em um desenho animado, o plano de expressão pode ser apresentado por um vínculo cromático, ou seja, pela sua manifestação das cores; o componente eidético, através do uso de linhas e pelo vínculo topológico, que pode ser pela sua representação ou distribuição pictórica na tela. 
A apresentação dos estudos sincréticos se faz necessária para compreensão dos termos e de como se dará a transição de aspectos do texto literário para o texto sincrético (animação).

\section{Do texto literário ao sincrético}

Com base nas análises feitas anteriormente é possível propor estudos que se constituem como definidores do plano de expressão do projeto de animação. A aplicação visual é concebida pelas categorias cromáticas e topológicas. Os sistemas semissimbólicos reforçam a contrariedade encontrada no plano de conteúdo alegria vs. aflição, conforme apontado no diagrama apresentado na sequência:

Figura 4 - Relações entre as categorias do plano de expressão com os efeitos nos planos de expressão e de conteúdo

\begin{tabular}{|c|c|c|}
\hline CATEGORIAS DO PLANO EXPRESSÃO & $\begin{array}{c}\text { EFEITO NO } \\
\text { PLANO EXPRESSÃO }\end{array}$ & $\begin{array}{l}\text { EFEITO NO, } \\
\text { PLANO CONTEÚDO }\end{array}$ \\
\hline $\begin{array}{l}\text { CROMÁTICA: } \\
\text { CORES COM BAIXA SATURAÇÃO vs } \\
\text { ALTA SATURAÇÃO }\end{array}$ & $\begin{array}{l}\text { CONTENÇÃO VS } \\
\text { EXPANSÃO }\end{array}$ & $\begin{array}{l}\text { AFLIÇÃO VS } \\
\text { ALEGRIA }\end{array}$ \\
\hline $\begin{array}{l}\text { EIDÉTICA: } \\
\text { FORMAS LINEARES VS FORMAS CURVAS }\end{array}$ & $\begin{array}{l}\text { ESTATICIDADE VS } \\
\text { DINAMICIDADE }\end{array}$ & $\begin{array}{l}\text { AFLIÇÃO VS } \\
\text { ALEGRIA }\end{array}$ \\
\hline $\begin{array}{l}\text { TOPOLÓGICA: } \\
\text { PLANO GERAL VS PLANO FECHADO }\end{array}$ & $\begin{array}{l}\text { DISTANCIAMENTO VS } \\
\text { APROXIMAÇÃO }\end{array}$ & $\begin{array}{l}\text { AFLIÇÃO VS } \\
\text { ALEGRIA }\end{array}$ \\
\hline
\end{tabular}

Fonte: Elaborado pelo autor.

Importante considerar que tais aspectos, no planejamento da animação, necessitam ser observados, uma vez que irão provocar, no expectador, as sensações e percepções desejadas. No início da história, a aflição domina a aldeia, o frio e a neve dificultam as famílias a terem acesso à comida e à lenha para se manterem aquecidos. Com a neve cobrindo quase tudo, o visual cromático é de cores com baixo nível de saturação. Havendo a solução da trama, as cores aumentam o nível de saturação cromática em toda a tela. Além disso, Mariazinha é apresentada com uma diversificação de cores, correspondentes ao seu desejo em trazer a alegria à aldeia. Ela vai até a floresta, onde o frio é mais concentrado. Na floresta, em virtude do frio, as cores são ofuscadas e limitadas, predominando o uso do branco e dos cinzas.

O componente topológico foi definido pelo distanciamento entre a câmera e os personagens, ou seja, pelo tipo de plano aberto ou fechado. Quando o clima é de 
aflição, os planos abertos predominam dentro da animação, ou seja, no momento em que a câmera realiza um afastamento do personagem, evidenciando o cenário em volta. Já quando a alegria é estabelecida, os planos fechados passam a dominar, colocando em evidência o personagem em relação ao cenário.

A função principal dos conteúdos semissimbólicos apresentados aqui é de tornar mais claros os sentidos que o texto quer transmitir. A sua aplicação no projeto de animação torna-se basilar, com o intuito de enriquecer o conteúdo audiovisual com aspectos do próprio texto literal, podendo transmitir a essência e os desdobramentos do conto para o texto sincrético.

\section{Semiótica no projeto de animação}

O conteúdo semiótico do projeto de animação encontrou na manifestação visual o viés para ser apresentado. O ponto fundamental de sentido analisado foi evidenciado com a oposição dos termos Alegria e Aflição. Portanto, as representações de sentido do texto literário foram compreendidas segundo a modalidade topológica e cromática.

$\mathrm{Na}$ categoria topológica a oposição alegria vs aflição foi representada pelo enquadramento de câmera. Quando a câmera produz um enquadramento de plano aberto ou geral, a manifestação de distanciamento do personagem principal compreende um instante de Aflição. Nos planos médio e primeiro plano, a manifestação de aproximação do personagem principal compreende um instante de Alegria.

A oposição dos termos fundamentais se manifesta, também, através da modalidade cromática. Em instantes de aflição as cores são com pouca saturação, mas quando existem instantes de Alegria, o nível de saturação cresce consideravelmente.

Um exemplo de instante de Aflição pode ser conferido na figura a seguir. 
Figura 5 - Instante de Aflição

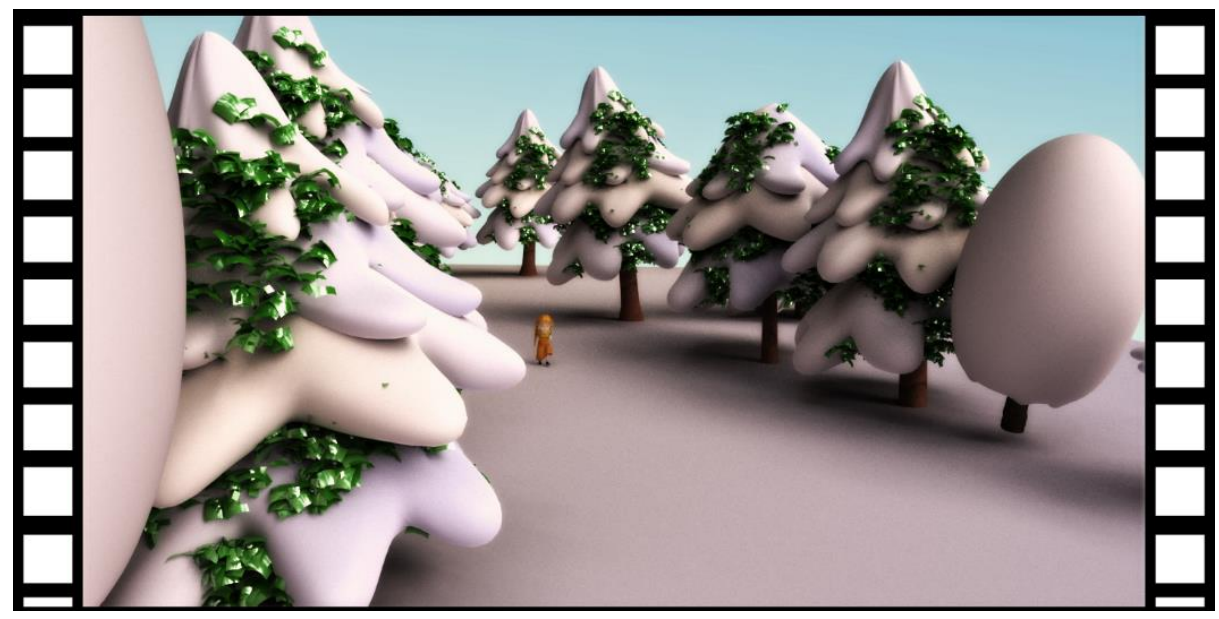

Fonte: Elaborado pelo autor.

O plano geral e as cores com pouca saturação transmitem o instante de Aflição presente no contexto no qual a personagem se encontra. Na sequência, a figura subsequente apresenta um exemplo de instante de Alegria.

Figura 6 - Instante de Alegria

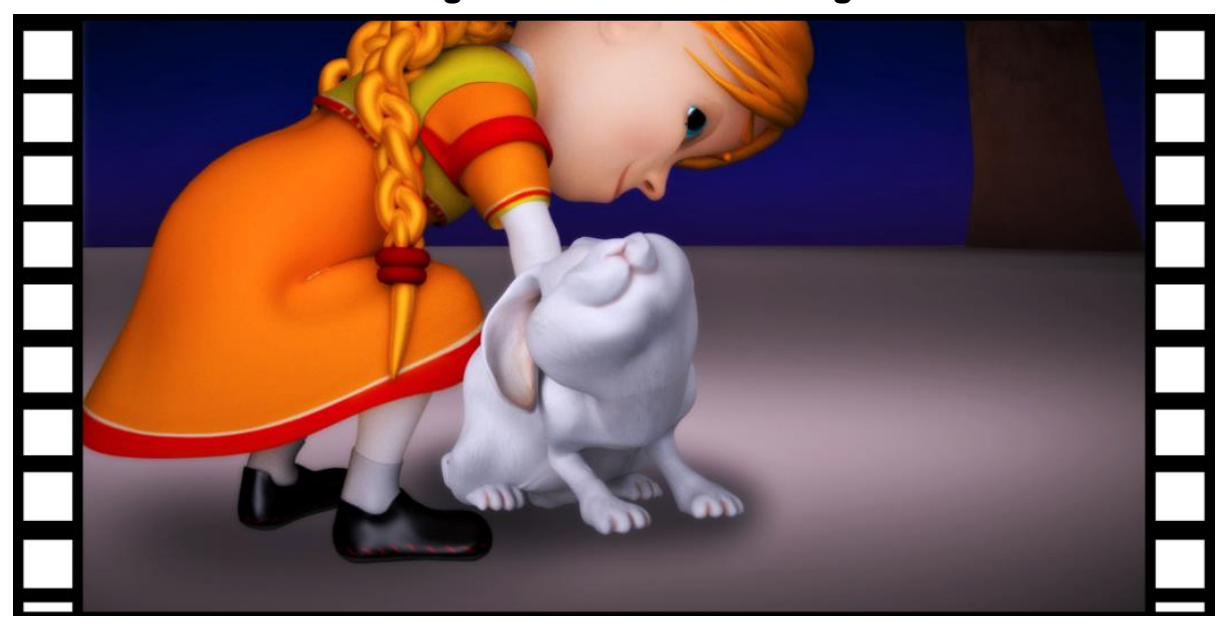

Fonte: Elaborado pelo autor.

O instante de manifestação alegre da personagem é transmitido pelo primeiro plano de enquadramento e com cores em um nível maior de saturação.

Durante toda a animação há essa contrariedade Aflição e Alegria, considerando que são representadas pelas modalidades topológica e cromática, de maneira similar ao exemplo aqui apresentado.

O Trailer da animação pode ser conferido no seguinte endereço https://www.youtube.com/watch?v=xReP57kKO_k. 


\section{Conclusão}

Relacionar a semiótica discursiva no processo de adaptação cinematográfica criou a possibilidade de olhar a narrativa por uma lógica de produção de sentidos muito mais ampla e clara. Isso teve uma grande repercussão no momento da produção, dando segurança na elaboração do curta-metragem em animação.

Nesse projeto audiovisual, os estudos com base na semiótica discursiva permitiram tangibilizar o conceito de oposição (Aflição vs. Alegria) no plano de conteúdo. Essa relação poderia ser aplicada das mais diversas maneiras no plano de expressão na animação, explorando ainda mais a plasticidade da linguagem. Mas tratando-se de um experimento, o compartilhamento deste tipo de estudo abre e estimula o modo de refletir e utilizar tais mecanismos de abordagem nas linguagens sincréticas, propondo uma imersão reflexiva, muito mais do que simplesmente separar e categorizar os elementos estruturantes do texto.

Essas aproximações preliminares, brevemente apontadas nesse artigo, demonstram um caminho de pensamento no texto para adaptação, que pode ser mais aprofundado, expandido e estudado, um exercício bem orientado de construção de sentido a partir do texto genuíno, o que resultará em uma poderosa reflexão predecessora ao roteiro audiovisual.

Os estudos relacionados à semiótica possibilitam um olhar diferenciado ao objeto de criação. Uma maneira de segregação das particularidades que estruturam o objeto como um todo. Esse é, portanto, um modo com o qual poderemos compreender e esmiuçar as formas de articulação das categorias plásticas, auditivas e rítmicas, permitindo-nos, paulatinamente, alargar a nossa percepção de maneira lógica e coerente.

A busca pelo sentido legítimo nos textos, na imagem, no âmbito do cinema, decorre de incessantes estudos, servindo-nos como caminho para compreensão cultural e social à qual estamos permanentemente submetidos. 


\section{Referências}

BARROS, Diana Luz Pessoa de. Teoria semiótica do texto. 4. ed. São Paulo: Ática, 1997.

FONTANILLE, Jacques. Semiótica do discurso. São Paulo: Contexto, 2007.

GREIMAS, A. J.; COURTÉS, J. Dicionário de semiótica. São Paulo: Contexto, 2008.

NÖTH, Winfried. A semiótica no século XX. 2. ed. São Paulo: Annablume, 1999.

OLIVEIRA, Ana Claudia; LANDOWSKI, Eric; FIORIN, José Luiz. Do inteligível ao sensível: em torno da obra de A. J. Greimas. São Paulo: EDUC, 1995.

OLIVEIRA, Ana Claudia. Linguagem na comunicação: desenvolvimentos de semiótica sincrética. São Paulo: Estação das Letras e Cores, 2009.

PIETROFORTE, Antonio Vicente. Semiótica visual: os percursos do olhar. São Paulo, Contexto, 2007.

SANTAELLA, Lúcia; NÖTH, Winfried; MENEZES, Philadelpho. O que é semiótica. São Paulo: Brasiliense, 1983.

SANTAELLA, Lucia. Semiótica aplicada. São Paulo: Cengage Learning, 2002.

SAUSSURE, Ferdinand. Curso de linguística geral. São Paulo: Cultrix, 1973.

SCHNEIDER, Adolfo Bernardo. O coelhinho do halo azul - rádio-sketch pré-natalino em um ato. Joinville/SC: s/ed., 1959.

\section{Diego Maria Cardoso}

Graduado em Design de Animação Digital pela Universidade da Região de Joinville (Univille). Atua há quatro anos na área da animação. É leitor compulsivo de correntes semióticas e do campo cinematográfico. É também leitor de autores como David Hume, Friedrich Schiller, Martin Heidegger entre outros.

E-mail: diegolk|@hotmail.com

\section{Rita Inês Petrykowski Peixe}

Doutora em Educação pela Universidade Federal do Rio Grande do Sul (UFRGS, 2012); Mestre em Educação pela Universidade de Campinas/Universidade do Contestado (UNICAMP/UnC, 2003). Especialista em Arte/Educação pela Universidade de Passo Fundo (UPF, 1999). Possui graduação em Educação Artística - Habilitação em Artes Plásticas pela Universidade do Oeste de Santa Catarina (UNOESC, 1995) e graduação em Pedagogia - Habilitação em Orientação Educacional pela Universidade do Oeste de Santa Catarina (UNOESC/UnC, 1995). Em 2011 desenvolveu Estágio de Doutorado em Barcelona/ Espanha (doutorado sanduíche) como bolsista da CAPES. Atualmente, atua como professora no Instituto Federal de Santa Catarina, IFSC de Itajaí.

E-mail: ritapeixe@hotmail.com

Currículo: http://lattes.cnpq.br/1094071355516986

Recebido em 17 de junho de 2016 Aceito em 13 de agosto de 2016 